\title{
Mapping of the Oat Crown Rust Resistance Gene Pc39 Relative to Single Nucleotide Polymorphism Markers
}

\author{
Jun Zhao, ${ }^{1,2}$ Aida Z. Kebede, ${ }^{1}$ Wubishet A. Bekele, ${ }^{3}$ Jim G. Menzies, ${ }^{1}$ James Chong, ${ }^{1}$ Jennifer W. Mitchell Fetch, ${ }^{4}$ Nicholas A. Tinker, ${ }^{3}$ \\ Aaron D. Beattie, ${ }^{5}$ Yuan-Ying Peng, ${ }^{2}$ and Curt A. McCartney ${ }^{1,}$ \\ ${ }^{1}$ Morden Research and Development Centre, Agriculture and Agri-Food Canada, Morden, Manitoba, Canada \\ ${ }^{2}$ Triticeae Research Institute, Sichuan Agricultural University, Wenjiang, Chengdu, China \\ ${ }^{3}$ Ottawa Research and Development Centre, Agriculture and Agri-Food Canada, Ottawa, Ontario, Canada \\ ${ }^{4}$ Brandon Research and Development Centre, Agriculture and Agri-Food Canada, Brandon, Manitoba, Canada \\ ${ }^{5}$ Department of Plant Sciences, Crop Development Centre, University of Saskatchewan, Saskatoon, Saskatchewan, Canada
}

\begin{abstract}
Crown rust, caused by Puccinia coronata f. sp. avenae Eriks. (Pca), is among the most important oat diseases resulting in significant yield losses in many growing regions. A gene-for-gene interaction is well established in this pathosystem and has been exploited by oat breeders to control crown rust. $P c 39$ is a seedling crown rust resistance gene that has been widely deployed in North American oat breeding. DNA markers are desired to accurately predict the specific $P c$ genes present in breeding germplasm. The objectives of the study were as follows: (i) to map Pc39 in two recombinant inbred line (RIL) populations (AC Assiniboia/ MN841801 and AC Medallion/MN841801) and (ii) to identify single nucleotide polymorphism (SNP) markers for postulation of Pc39 in oat germplasm. $P c 39$ was mapped to a linkage group consisting of 16 SNP markers, which placed the gene on linkage group Mrg11 (chromosome 1C) of the oat consensus map. Pc39 cosegregated with SNP marker

GMI_ES01_c12570_390 in the AC Assiniboia/MN841801 RIL population and was flanked by the SNP markers avgbs_126086.1.41 and GMI_ES15 c276_702, with genetic distances of 1.7 and $0.3 \mathrm{cM}$, respectively. In the AC Medallion/MN841801 RIL population, similar results were obtained but the genetic distances of the flanking markers were 0.4 and $0.4 \mathrm{cM}$, respectively. Kompetitive Allele-Specific PCR assays were successfully designed for Pc39-linked SNP loci. Two SNP loci defined a haplotype that accurately predicted $P c 39$ status in a diverse panel of oat germplasm and will be useful for marker-assisted selection in oat breeding.

Keywords: Avena sativa, cereals and grains, crown rust, cultivar/ resistance, disease management, fungi, field crops, marker-assisted selection, oat, pathogen diversity, Pc39, Puccinia coronata f. sp. avenae, single nucleotide polymorphism
\end{abstract}

Oat (Avena sativa L.) is an important cereal crop grown in many regions of the world. This crop is used for human food and livestock consumption (Gnanesh et al. 2013; Simons 1985) and is increasingly receiving interest because of its nutritional benefits. Crown rust is caused by the fungus Puccinia coronata f. sp. avenae Eriks. (Pca) and is a common disease of oat that can cause severe damage (Simons 1985). In Canada, oat crown rust is most common in the eastern prairie region (Manitoba and eastern Saskatchewan), southern Ontario, and southwestern Quebec (Chong and Brown 1996; McCartney et al. 2011). Estimated yield losses in the eastern prairie region in 2001 to 2005 averaged $5.1 \%$ annually, with yield losses up to 11.2 and $8.8 \%$ reported in 2001 and 2005, respectively (Chong et al. 2008). In the United States, $20 \%$ yield losses have been reported in Minnesota and Louisiana (Carson 2011). Although crown rust outbreaks can be reduced by a combination of several methods, such as elimination of alternate hosts (Rhamnus spp.), early seeding, and incrop foliar fungicide application, the development of cultivars with host resistance is recognized as the most effective, efficient, economical,

${ }^{\dagger}$ Corresponding author: C. A. McCartney; curt.mccartney@canada.ca

Funding: This work was supported by the China Scholarship Council, Prairie Oat Breeding Consortium, Agriculture and Agri-Food Canada, and Prairie Oat Growers Association.

*The $\boldsymbol{e}$-Xtra logo stands for "electronic extra" and indicates that one supplementary figure and two supplementary tables are published online.

The author(s) declare no conflict of interest.

Accepted for publication 22 November 2019.

(c) Her Majesty the Queen in Right of Canada, as represented by the Minister of Agriculture and Agri-Food Canada. and environmentally friendly method to manage this disease (McCallum et al. 2007; McCartney et al. 2011; Nazareno et al. 2018; Simons 1970). A gene-for-gene interaction underlies the host-pathogen interactions in the oat-Pca pathosystem, with evidence of physiological specialization dating back 100 years (Hoerner 1919). The lifespan of a new and widely deployed resistance gene has often been 5 years or less as the result of increased frequency of $P c a$ races virulent on the new resistance gene (Carson 2011; Nazareno et al. 2018).

Cultivars with race-specific, seedling resistance genes have been the primary means to control crown rust in North America (Gnanesh et al. 2014; Nazareno et al. 2018). These genes have been deployed either singly or in combinations. There are more than 100 described resistance genes designated with $P c$ gene symbols to date (Cabral et al. 2014; Sanz et al. 2013), but many could be the same or allelic because their chromosomal locations have not been determined. Most $P c$ genes are dominant, but some are partially dominant or recessive (Cabral et al. 2014; Simons et al. 1978). Initially, breeders utilized $P c$ genes from cultivated oat to develop new resistant cultivars (Gnanesh et al. 2013; Martens and Dyck 1989). Many $P c$ genes have been introgressed and deployed from accessions of the wild hexaploid A. sterilis collected in Israel and other Mediterranean countries during the 1960s and the early 1970s (Leonard et al. 2004). More than 16 genes from A. sterilis have been utilized in oat cultivars in North America (Leonard 2003). In the eastern prairie region of Canada, $P c 38, P c 39, P c 48$, and $P c 68$ have been deployed in oat cultivars and remain common (McCallum et al. 2007). Pc39 was introgressed into cultivated oat from the A. sterilis accession F366 collected in Israel (Fleischmann and McKenzie 1968) and was the first $A$. sterilis $P c$ gene to be used in Canada resulting in the release of cultivar Fidler in 1980 (McKenzie et al. 1981). Subsequently, the $P c 38$ and $P c 39$ genes were deployed in combination in the cultivars Dumont, Riel, Robert, AC Marie, AC Preakness, and Rebel from 1982 to 1993 (McCallum et al. 2007). Pc68 was later added to develop cultivars with the $P c 38 / 39 / 68$ gene pyramid. The 
first of these cultivars was AC Assiniboia (Brown et al. 2001), which was followed by AC Medallion, Pinnacle, and Ronald (Duguid et al. 2001; Mitchell Fetch et al. 2003a, b).

Pc39 is a dominant crown rust resistance gene effective at the seedling growth stage (Fleischmann and McKenzie 1968) that has been mapped relative to restriction fragment length polymorphism (RFLP) markers (Wight et al. 2005). Virulence to the Pc38/39 gene combination was $>87 \%$ by 1992 on the Canadian prairies (Chong and Seaman 1994). During 2002 to 2006, 57 to 93\% isolates from wild oat in the prairie region were virulent to Pc38 and Pc39 (Chong et al. 2008). Yet in other regions of the world, $P c 39$ maintains relatively high effectiveness to the native $P c a$ population. For instance, $P c a$ isolates collected from field trials at five locations in the Czech Republic from 2004 to 2006, 0 of $79 P c a$ isolates were virulent on $P c 39$ and the resistance gene was recommended for use in oat breeding (Jiráková and Hanzalová 2008). Similarly, Pc39 was highly resistant to natural $P c a$ populations in field trials in Tunisia, with virulence present at low levels in 1 of 24 environments (Hammami et al. 2010). Paczos-Grzęda and Sowa (2019) assessed virulence using Polish $P c a$ isolates collected from 2013 to 2015. A total of $31 \%$ (2014), 16\% (2015), and 16\% (2016) of Pca isolates were virulent on $P c 39$. Virulence data in other growing regions were not available. However, Pc39 is likely useful in many growing regions where the gene has not been previously deployed. In such situations, Pc39 should be deployed in combination with other effective $P c$ genes to prevent an increase in virulence to Pc39.

Pyramiding major resistance genes is seen as a valid strategy to prolong the effectiveness and durability of race-specific seedling resistance genes and has attracted the interest of oat breeders and pathologists. Resistance gene pyramids can be identified in indoor seedling inoculations with carefully selected $P c a$ isolates. One isolate is needed for each gene desired in the pyramid, in which this isolate is avirulent on the targeted gene and virulent on the other genes in the pyramid. This strategy is not practical to pyramid three or more Pc genes or to pyramid $P c$ genes to which no virulence exists. Marker-assisted selection (MAS) simplifies the pyramiding of resistance genes because any number of resistance genes can be identified, provided that closely linked markers have been developed. DNA markers are available for $>18$ oat crown rust resistance genes (Gnanesh et al. 2014). The chromosome location of many $P c$ genes is not known, since a chromosome-anchored linkage map was only recently developed in 2013 (Bekele et al. 2018; Chaffin et al. 2016; Oliver et al. 2013). This has hampered the identification of the allelic relationships among the $P c$ genes. The crown rust resistance genes Pc91 (Gnanesh et al. 2013), PcKM (Gnanesh et al. 2015), Pc45 (Kebede et al. 2018), Pc53 (Admassu-Yimer et al. 2018), and an adult plant resistance gene derived from MN841801 (Lin et al. 2014) were mapped relative to single nucleotide polymorphism (SNP) markers, which positioned these genes in the oat genome. There is a strong need in oat breeding and genetics to map all $P c$ genes onto the oat genetic map to reveal allelic relationships and identify linkages among $P c$ genes and other economically important genes. This knowledge will facilitate the construction of desirable gene combinations.

The objectives of this study were as follows: (i) to study the inheritance of the major seedling resistance gene Pc39 in the cultivars AC Assiniboia and AC Medallion, (ii) to genetically map the resistance gene to a specific oat chromosome, (iii) to develop Kompetitive Allele-Specific PCR (KASP) markers suitable for MAS of Pc39, and (4) to evaluate the effectiveness of these KASP markers to predict $P c 39$ status in a diverse panel of oat germplasm.

\section{Materials and Methods}

Plant material. The segregation of the seedling crown rust resistance gene Pc39 was investigated in two recombinant inbred line (RIL) populations with varying numbers of progeny. The two populations were derived from the crosses AC Assiniboia/MN841801 (AsbMN) and AC Medallion/MN841801 (MedMN), of which the AsbMN population consisted of $143 \mathrm{~F}_{8}$-derived RILs and the MedMN population consisted of $121 \mathrm{~F}_{6}$-derived RILs. AC
Assiniboia (pedigree $=P c 68 / 7 *$ Robert) is a tan-hulled oat $($ A sativa L.) cultivar developed at the former Cereal Research Centre (Agriculture and Agri-Food Canada) in Winnipeg, Canada (Brown et al. 2001). AC Medallion (pedigree $=P c 68 / 7 *$ Dumont) is a whitehulled oat (A. sativa L.) cultivar also developed at the former Cereal Research Centre (Duguid et al. 2001). Both AC Assiniboia and AC Medallion possess the crown rust resistance gene combination $P c 38, P c 39$, and $P c 68$, which was highly effective against the $P c a$ population on the Canadian prairies at the time of registration of these cultivars. The MN841801 experimental oat line was developed by Paul Rothman at the University of Minnesota in the early 1970s. This line has been resistant to diverse populations of crown rust in rust nurseries for $>35$ years (Leonard 2002). The pedigree of MN841801 is MN841801 Florad/Coker 58-7/3/CI7558//Black Mesdag/Aberdeen 101. The differential lines for $P c 38$ (pedigree $=$ CAV 2648-4/4*Pendek), Pc39 (pedigree = CAV 5165/4*Pendek), and $P c 68$ (pedigree $=$ Makuru $* 2 / / \mathrm{CAV} 4904 / 2 *$ Sun II) were also included as checks for inoculation experiments.

A panel of 74 crown rust-susceptible oat lines and cultivars from the Collaborative Oat Research Enterprise (CORE) project (Esvelt Klos et al. 2017) were used for haplotype analysis with the goal of identifying KASP assays useful for MAS of $P c 39$. The susceptibility of these oat cultivars and breeding lines was verified by testing them with the same $P c a$ isolate, 2015118 (race LMBG), that was used to map Pc39. Leaf tissue collection and DNA extraction was conducted as outlined below. These oat lines were tested with KASP assays interrogating SNPs linked to $P c 39$.

Evaluation of crown rust reaction. $P c a$ isolate 2015118 (race LMBG; virulence/avirulence formula $=P c 38,40,56,68 / 39,45$, $46,48,50,51,52,54,58,59,62,64)$ was used to study the segregation of $P c 39$ in two RIL populations (AsbMN and MedMN) and 74 oat lines in the haplotype panel. Pca isolate 2015118 was collected in the eastern Prairie region of western Canada in August 2015 from wild oat (A. fatua). Seedlings were inoculated at the one-leaf stage by spraying urediniospores $(4 \mathrm{mg} / 450 \mu \mathrm{l})$ suspended in light industrial oil (Bayol; Esso Canada, Toronto, ON, Canada) onto the leaves of the plants. Approximately five seedlings from each RIL of the AsbMN and MedMN populations were inoculated in independent experiments. The AsbMN population was inoculated in two experiments (i.e., 10 plants tested per RIL), whereas the MedMN population was inoculated in a single experiment (i.e., five plants tested per RIL). Inoculated plants were incubated in a Percival model I-60D dew chamber (Percival Scientific, Perry, IA, USA) overnight at $15^{\circ} \mathrm{C}$ and then transferred to a greenhouse with the temperature maintained between 18 and $22^{\circ} \mathrm{C}$ and $16 \mathrm{~h}$ of daylight supplemented with high-pressure sodium lighting (canopy-level light intensity = $450 \mu \mathrm{mol} \mathrm{m} \mathrm{m}^{-2} \mathrm{~s}^{-1}$ ). Crown rust infection type (IT) was scored 12 to 14 days after inoculation on a 0 to 4 scale (Murphy 1935): IT scores of 0 (immune),; (fleck), 1, and 2 were considered resistant, and ITs of 3 and 4 were considered susceptible.

DNA marker analyses. After disease symptoms were rated, leaf tissue was collected from the third and fourth leaves (i.e., noninfected) into envelopes. The tissue was lyophilized and stored at $-80^{\circ} \mathrm{C}$ until DNA extraction. High-quality genomic DNA was extracted from this lyophilized tissue using the DNeasy Plant DNA extraction kit (Qiagen, Toronto, ON, Canada). DNA was quantified using the fluorescent dye Hoechst 33258. Fluorescence was measured with a Tecan Infinite 135 F500 reader (Tecan Group Ltd., Männedorf, Switzerland).

The AsbMN population, AC Assiniboia, AC Medallion, and MN841801 were genotyped using genotyping-by-sequencing (GBS) following the protocol described by previous researchers (Huang et al. 2014). Genomic DNA was digested using two restriction enzymes, PstI (CTGCAG) and MspI (CCGG), and barcoded adaptors were ligated to each DNA sample in a 96-well plate. The 96 samples of a plate were then pooled into a single library and amplified by PCR. Two pooled libraries were generated to accommodate the number of genotypes tested in this study. A single midoutput lane of NextSeq 500 (Illumina, San Diego, CA, USA) was used to sequence each pooled library. Single-end sequenced 
reads of 150 bases were generated. Haplotag software (Tinker et al. 2016) was used to call haplotype-based SNPs at approximately 240,000 loci. The AsbMN population was previously genotyped with the $6 \mathrm{~K}$ oat (Tinker et al. 2014) and 90K wheat (Wang et al. 2014) Infinium iSelect SNP assays (Lin et al. 2014). All genotyping data were merged to construct a new linkage map for the AsbMN population, which identified SNPs linked to Pc39.

KASP markers were designed for Pc39-linked SNPs (GBS and 6K oat Infinium) using PrimerPicker Lite software (LGC Genomics LLC, Beverly, MA, USA) and tested on both RIL populations (Supplementary Table S1). The KASP assay included $2.5 \mu 1$ of DNA $(15 \mathrm{ng} / \mu \mathrm{l}), 2.5 \mu \mathrm{l}$ of $2 \times \mathrm{KASP}$ reaction mix, and $0.07 \mu \mathrm{l}$ of primer mix. Each primer mix consisted of two forward primers and one

Table 1. Segregation ratios of the AC Assiniboia/MN841801 (AsbMN) and AC Medallion/MN841801 (MedMN) recombinant inbred line (RIL) populations when inoculated with crown rust isolate $2015118^{\mathrm{a}}$ (race LMBG ${ }^{\mathrm{b}}$ )

\begin{tabular}{lcccccc}
\hline $\begin{array}{l}\text { RIL } \\
\text { population }\end{array}$ & HR $(\boldsymbol{n})^{\mathbf{c}}$ & $\begin{array}{c}\text { Segregating } \\
(\boldsymbol{n})\end{array}$ & $\begin{array}{c}\text { HS } \\
(\boldsymbol{n})^{\mathbf{d}}\end{array}$ & $\begin{array}{c}\text { HR/HS } \\
\text { ratio }\end{array}$ & $\boldsymbol{\chi}^{\mathbf{2}}$ & $\begin{array}{c}\boldsymbol{P} \\
\text { value }\end{array}$ \\
\hline AsbMN & 80 & 3 & 60 & $1: 1$ & 2.64 & 0.10 \\
MedMN & 61 & 1 & 59 & $1: 1$ & 0.03 & 0.86 \\
\hline
\end{tabular}

a Crown rust isolate number at Morden Research and Development Centre.

${ }^{\mathrm{b}}$ Race designation according to the standard North American system of nomenclature of Pca (Chong et al. 2000).

${ }^{c} \mathrm{HR}=$ homozygous resistant.

${ }^{\mathrm{d}} \mathrm{HS}=$ homozygous susceptible. reverse primer diluted to a concentration of $100 \mathrm{pmol} / \mu \mathrm{l}$. A $5-\mu \mathrm{l}$ reaction volume was used for PCR with the following conditions: initial denaturation at $94^{\circ} \mathrm{C}$ for $15 \mathrm{~min}, 94^{\circ} \mathrm{C}$ for $20 \mathrm{~s}, 10$ touchdown cycles over 61 to $55^{\circ} \mathrm{C}$ for $1 \mathrm{~min}$ (dropping down by $0.6^{\circ} \mathrm{C}$ per cycle), and 26 cycles of $20 \mathrm{~s}$ at $94^{\circ} \mathrm{C}$ followed by an extension for $1 \mathrm{~min}$ at $55^{\circ} \mathrm{C}$. PCR samples were maintained in the dark at $4^{\circ} \mathrm{C}$ until an Omega FLUOstar scanner (BMG LABTECH GmbH, Offenburg, Germany) determined the fluorescence of each sample. KlusterCaller software (LGC Genomics LLC) analyzed the fluorescence data to identify clusters for scoring SNP alleles.

Statistical and linkage analyses. For each RIL population, the crown rust IT data were tested for fit to Mendelian segregation ratios by $\chi^{2}$ analysis. Linkage maps were constructed with MapDisto version 1.7.7 software (Lorieux 2012). Genotypes and markers with $>10 \%$ missing marker data and heterozygous RILs were excluded from linkage analysis. A minimum logarithm of odds score of 3 and a maximum recombination fraction of 0.3 were used as criteria to determine linkage groups. The Kosambi mapping function (Kosambi 1943) was used to convert recombination fractions to centimorgans. MapChart 2.1 software (Voorrips 2002) was used to illustrate linkage maps.

\section{Results}

Segregation of crown rust reaction. The Pc39 differential line and the Pc39 donor parents AC Assiniboia and AC Medallion had resistant IT scores (IT score $=$; or ; 1 ) when inoculated with $P c a$ isolate 2015118 (race LMBG) in the seedling inoculation experiments

\section{Consensus Map}

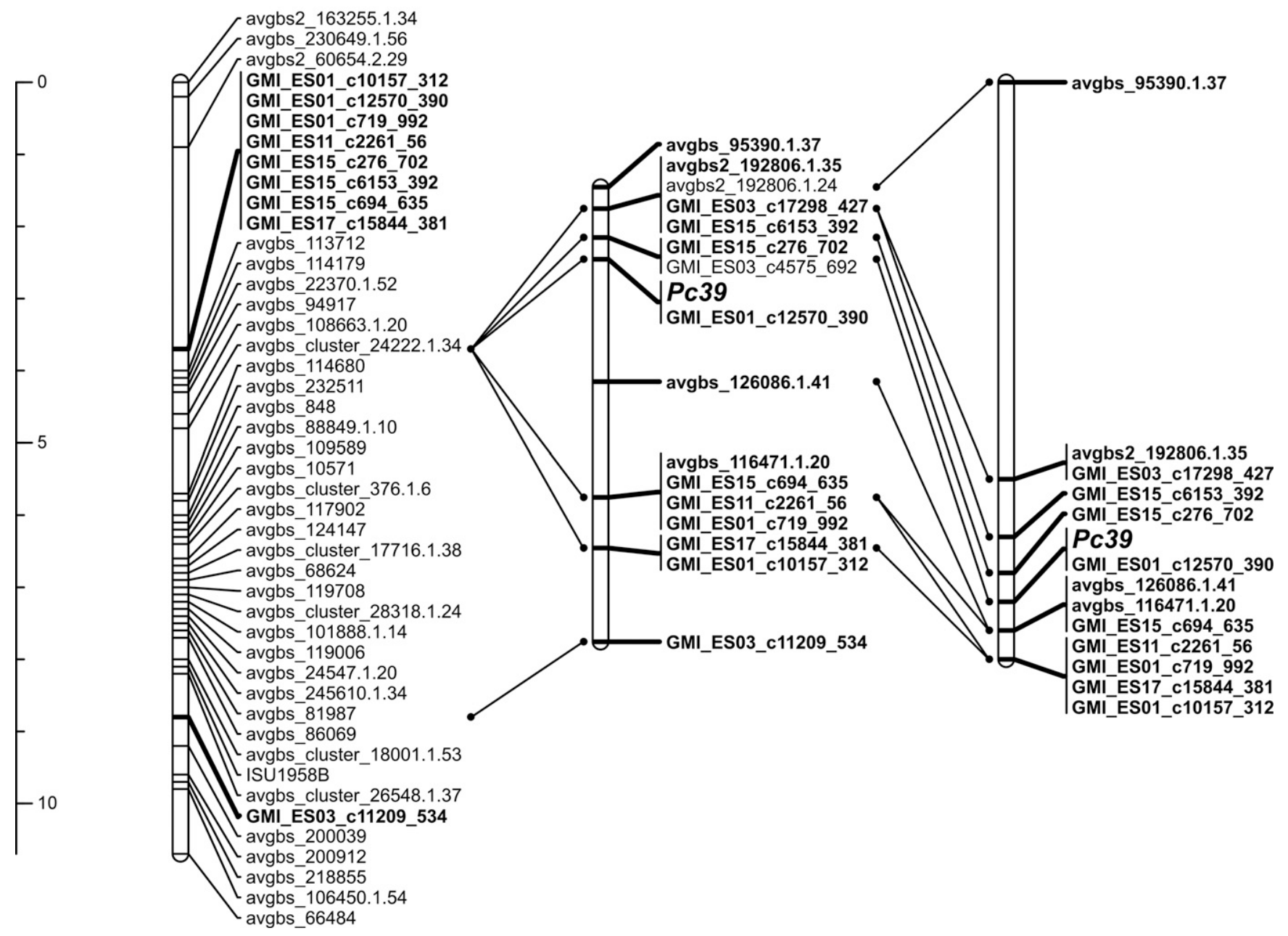

MedMN

Fig. 1. Linkage maps showing the common location of the Pc39 crown rust resistance gene. "Consensus Map" refers to Mrg11 (chromosome 1C) of the chromosome-anchored consensus genetic map (Bekele et al. 2018). Loci in bold are present in more than one linkage map. Lines between linkage maps highlight the colinearity of the maps. The ruler on the left of the linkage maps is scaled in centimorgans. 
(Supplementary Fig. S1). The Pc38 and Pc68 differential lines and the parent MN841801 had the same IT as the susceptible control cultivar Makuru (IT score = 4). The AC Assiniboia/MN841801 (AsbMN) RIL population segregated 80 homozygous resistant (HR), three segregating, and 60 homozygous susceptible (HS), which is consistent with a single gene controlling resistance (Table 1). The AC Medallion/MN841801 (MedMN) RIL population segregated $61 \mathrm{HR}$, one segregating, and $59 \mathrm{HS}$, which is also consistent with a single gene controlling resistance (Table 1). Both of the mapping populations (AsbMN and MedMN) fit a 1:1 resistant/ susceptible segregation ratio, indicating a single segregating gene. The reactions of the parents and differential lines indicate that the segregating gene was $P c 39$.

Pc39 marker development and linkage analysis. The parental lines and the AsbMN RIL population were genotyped using GBS in this study and were previously genotyped with the $6 \mathrm{~K}$ oat and 90K wheat Infinium iSelect SNP assays (Lin et al. 2014). Among these, a total of 522 SNP loci were identified to be linked to Pc39. Sixteen SNPs closely linked to $P c 39$ were selected for KASP marker development. The sequences of the KASP PCR primers are reported in Supplementary Table S1. Using these data, a linkage group was created for the AsbMN mapping population using the Pc39 scoring data and 16 newly designed KASP markers (Fig. 1). Pc39 cosegregated with KASP marker GMI_ES01_c12570_390_kom235 and was bracketed by markers avgbs_126086.1.41_kom234 and GMI ES15_c276_702_kom 237 with genetic distances of 1.7 and $0 . \overline{3}$ cM, respectively. The AsbMN Pc39 linkage map including all SNP loci is presented in Supplementary Table S2. To confirm these results, the 16 KASP markers were tested in the MedMN population. Thirteen of 16 markers were polymorphic between the parental lines and were mapped in this population (Fig. 1). Again, Pc39 cosegregated with KASP marker GMI_ES01_c12570_390_kom235 and was flanked by the markers avgbs_126086.1.41_kom234 and GMI ES15_c276_702_kom237 with genetic distances of 0.4 and

Table 2. Evaluation of the predictive accuracy of single nucleotide polymorphism markers linked to the Pc39 gene in a diverse set of oat lines

\begin{tabular}{|c|c|c|c|c|c|c|c|c|c|c|c|c|c|c|}
\hline Oat line & $\mathbf{I T}^{\mathbf{a}}$ & $\begin{array}{c}\text { Pc39 } \\
\text { carrier }\end{array}$ & $\begin{array}{c}\text { avgbs_ }_{-} \\
95390.1 .37 \\
\text { kom } 242\end{array}$ & $\begin{array}{c}\text { avgbs2_- } \\
\text { 192806.1.35_- } \\
\text { kom241 }\end{array}$ & $\begin{array}{c}\text { GMI_ } \\
\text { ES03_- } \\
\text { c17298_- } \\
427_{-} \\
\text {kom238 }\end{array}$ & $\begin{array}{c}\text { GMI_- } \\
\text { ES15_- } \\
\text { c6153_- } \\
392 \_ \\
\text {kom239 }\end{array}$ & $\begin{array}{c}\text { GMI_- } \\
\text { ES15_- } \\
\text { c276_- } \\
702 \_ \\
\text {kom237 }\end{array}$ & $\begin{array}{c}\text { GMI_- } \\
\text { ES01_- } \\
\text { c12570_- } \\
\text { 390_- } \\
\text { kom235 }\end{array}$ & $\begin{array}{c}\text { avgbs_ }_{-} \\
\text {126086.1.41_- } \\
\text { kom } 234\end{array}$ & $\begin{array}{c}\text { GMI_- } \\
\text { ES15_- } \\
\text { c694_- } \\
635 \_ \\
\text {kom231 }\end{array}$ & $\begin{array}{c}\text { GMI_- } \\
\text { ES11_- } \\
\text { c2261_- } \\
56 \_ \\
\text {kom230 }\end{array}$ & $\begin{array}{c}\text { GMI_- } \\
\text { ES01_- } \\
\text { c719_- } \\
992 \_ \\
\text {kom229 }\end{array}$ & $\begin{array}{c}\text { GMI_- } \\
\text { ES01_- } \\
\text { c10157_- } \\
312- \\
\text { kom228 }\end{array}$ & $\begin{array}{c}\text { GMI_- } \\
\text { ES03_- } \\
\text { c11209_ } \\
534 \\
\text { kom227 }\end{array}$ \\
\hline $\begin{array}{l}\text { AC } \\
\text { Assiniboia }\end{array}$ & ; & Yes & $A^{b}$ & $\mathrm{~A}$ & $\mathrm{~A}$ & $\mathrm{~A}$ & $\mathrm{~A}$ & $\mathrm{~A}$ & $\mathrm{~A}$ & $\mathrm{~A}$ & $\mathrm{~A}$ & $\mathrm{~A}$ & $\mathrm{~A}$ & $\mathrm{~A}$ \\
\hline $\begin{array}{l}\mathrm{AC} \\
\text { Medallion }\end{array}$ & ; & Yes & A & A & A & A & A & A & A & A & A & A & A & B \\
\hline Makuru & 4 & No & B & B & A & B & B & B & A & B & A & A & A & B \\
\hline MN841801 & 4 & No & B & B & B & B & B & B & B & B & B & B & B & B \\
\hline $00 \mathrm{Ab} 7006$ & 4 & No & B & A & B & B & B & B & A & - & $\mathrm{A}$ & A & A & B \\
\hline $00 \mathrm{Ab} 7085$ & 4 & No & B & A & B & B & B & B & A & A & A & A & A & B \\
\hline 02Ab6655 & 4 & No & B & A & B & B & B & B & A & A & A & A & A & B \\
\hline 02HO-139 & 4 & No & B & A & B & B & B & B & A & A & $\mathrm{A}$ & A & A & B \\
\hline $95 \mathrm{Ab} 12770$ & 4 & No & B & B & A & B & B & B & A & A & A & A & A & B \\
\hline $95 \mathrm{Ab} 13050$ & 4 & No & B & A & B & B & B & B & A & A & A & A & A & B \\
\hline $98 \mathrm{Ab} 7265$ & 4 & No & B & A & B & B & B & B & A & A & A & A & A & B \\
\hline 99Ab10937 & 4 & No & A & A & A & B & B & B & A & - & A & A & - & B \\
\hline 99Ab10987 & 3 & No & B & $\mathrm{A}$ & B & B & B & B & A & $\mathrm{A}$ & A & A & $\mathrm{A}$ & B \\
\hline 99Ab11098 & 4 & No & B & A & B & B & B & B & A & $\mathrm{A}$ & $\mathrm{A}$ & A & $\mathrm{A}$ & B \\
\hline 99Ab11227 & 3 & No & B & A & B & B & B & B & A & A & A & A & A & B \\
\hline 99Ab11391 & 4 & No & B & A & B & B & B & B & A & A & A & A & A & B \\
\hline Andrew & 4 & No & A & A & $\mathrm{A}$ & B & B & B & A & B & B & B & B & B \\
\hline ARDENTE & 4 & No & B & A & A & B & B & B & A & B & $\mathrm{A}$ & A & A & B \\
\hline BARRA & 4 & No & B & $\mathrm{A}$ & $\mathrm{A}$ & B & B & B & A & B & $\mathrm{A}$ & A & $\mathrm{A}$ & B \\
\hline Biri & 4 & No & B & A & B & B & $\mathrm{A}$ & B & A & B & B & A & - & A \\
\hline Bond & 4 & No & A & B & B & B & A & A & A & - & B & A & B & A \\
\hline $\begin{array}{l}\text { Brown 1409- } \\
164\end{array}$ & 4 & No & B & A & B & B & A & A & A & B & B & A & B & A \\
\hline Bullion & 4 & No & B & B & A & B & B & B & A & $\mathrm{B}$ & A & $\mathrm{A}$ & A & B \\
\hline CILLA & 4 & No & B & $\mathrm{A}$ & A & B & B & B & A & B & A & A & A & B \\
\hline CIRCLE & 4 & No & B & A & A & B & B & B & A & B & A & A & A & B \\
\hline Columbia & 4 & No & $\mathrm{B}$ & $\mathrm{B}$ & B & B & A & A & A & B & B & A & - & A \\
\hline Derby & 4 & No & B & B & A & B & B & B & A & $\mathrm{B}$ & A & A & A & B \\
\hline Firth & 4 & No & $\mathrm{A}$ & A & A & A & $\mathrm{A}$ & B & A & A & $\mathrm{B}$ & A & $\mathrm{B}$ & B \\
\hline FREJA & 4 & No & B & $\mathrm{A}$ & B & B & $\mathrm{A}$ & $\mathrm{A}$ & A & A & $\mathrm{A}$ & $\mathrm{A}$ & A & B \\
\hline Gere & 4 & No & B & A & $\mathrm{A}$ & B & B & B & A & A & A & A & A & B \\
\hline GN04399 & 4 & No & B & A & A & B & B & B & $\mathrm{A}$ & B & A & A & A & B \\
\hline Grane & 4 & No & B & A & A & B & B & B & A & B & A & A & A & B \\
\hline Grenader & 4 & No & B & B & B & B & $\mathrm{A}$ & A & A & B & B & $\mathrm{A}$ & B & $\mathrm{A}$ \\
\hline GUNHILD & 4 & No & B & B & $\mathrm{A}$ & B & B & B & A & B & A & A & - & B \\
\hline $\begin{array}{l}\text { HA05AB34- } \\
\quad 48\end{array}$ & 3 & No & B & A & A & B & B & B & A & A & A & $\mathrm{A}$ & A & B \\
\hline $\begin{array}{l}\text { HA05AB35- } \\
\quad 16\end{array}$ & 3 & No & B & A & B & B & B & B & A & A & A & A & A & B \\
\hline $\begin{array}{l}\text { HA05AB36- } \\
33\end{array}$ & 4 & No & B & A & A & B & A & B & A & B & A & $\mathrm{A}$ & B & B \\
\hline $\begin{array}{l}\text { HA05AB38- } \\
22\end{array}$ & 3 & No & B & A & B & B & B & B & A & A & A & A & A & B \\
\hline $\begin{array}{l}\text { HA05AB41- } \\
\quad 38\end{array}$ & 4 & No & B & A & A & B & B & B & A & A & A & A & A & B \\
\hline
\end{tabular}

a Infection type (IT) based on inoculation with oat crown rust isolate 2015118 (race LMBG). IT scores of 0 (immune), ; (fleck), 1 , and 2 were considered resistant, and ITs of 3 and 4 were considered susceptible.

${ }^{\mathrm{b}} \mathrm{A}$ is the AC Assiniboia allele, $\mathrm{B}$ is the MN841801 allele, and - is missing data. 
$0.4 \mathrm{cM}$, respectively. Comparison of the present linkage maps with the previously published oat consensus genetic map (Bekele et al. 2018) showed that Pc39 was located on linkage group Mrg11 of the oat consensus map (chromosome 1C) at $3.7 \mathrm{cM}$ (Fig. 1).

Evaluation of $P$ c39-linked SNPs in diverse germplasm. A set of 74 oat lines and cultivars from the CORE project (Esvelt Klos et al. 2017) were tested with 12 of the newly developed KASP markers closely linked to Pc39 (Table 2). These CORE lines were planted in the greenhouse and inoculated with crown rust isolate 2015118 (race LMBG). AC Assiniboia and AC Medallion were resistant to this isolate because of the presence of Pc39 as described above, whereas the remaining oat lines were susceptible and did not carry Pc39. Genotyping results revealed that the markers GMI_ES15_c6153 392_kom239 (prediction accuracy $=97 \%$ ), avgbs_95390.1.37_kom242 (prediction accuracy $=85 \%$ ), and GMI_ES03_c11209_534_kom227 (prediction accuracy $=85 \%$ ) were the most predictive of $P c 39$ since the AC Assiniboia allele was detected in only a few of the susceptible lines for these markers. Together GMI_ES15_c6153_392_kom239 (approximately $0.8 \mathrm{cM}$ from Pc39) and GMI_ES01_c12570_390_ kom235 (cosegregating with $P c 39$ ) correctly differentiated the $P c 39$ status of all of these oat lines. These two markers will be useful for MAS.

\section{Discussion}

The current study developed new KASP markers tightly linked to the crown rust resistance gene $P c 39$ in two RIL populations. Pc39 was also placed on linkage group Mrg11 (chromosome 1C) of the oat consensus map. Several newly designed KASP markers accurately predicted most of the oat lines that are susceptible to the $P \mathrm{Ca}$ race LMBG. These markers will be useful for MAS of $P c 39$ and will facilitate pyramiding $P c 39$ with other $P c$ genes in future breeding. The genes $P c 39$ and $P c 55$ were previously reported to be very closely linked or allelic (Kiehn et al. 1976), so the SNP markers developed in this study could also be used to map Pc55 and confirm the association

Table 2. (Continued from previous page)

\begin{tabular}{|c|c|c|c|c|c|c|c|c|c|c|c|c|c|c|}
\hline Oat line & $\mathrm{IT}^{\mathbf{a}}$ & $\begin{array}{c}\text { Pc39 } \\
\text { carrier }\end{array}$ & $\begin{array}{c}\text { avgbs }_{-} \\
95390.1 .37 \\
\text { kom 242 }\end{array}$ & $\begin{array}{c}\text { avgbs2 } \\
192806.1 .35 \\
\text { kom } 241\end{array}$ & $\begin{array}{c}\text { GMI_- } \\
\text { ESO3- }_{-} \\
\text {c17298}_{-} \\
427_{-} \\
\text {kom238 }\end{array}$ & $\begin{array}{c}\text { GMI } \\
\text { ES15_ }_{-} \\
\text {c6153 }_{-} \\
392_{-} \\
\text {kom239 }\end{array}$ & $\begin{array}{c}\text { GMI_- } \\
\text { ES15_- } \\
\text { c276_- } \\
702_{-} \\
\text {kom237 }\end{array}$ & $\begin{array}{c}\text { GMI_- } \\
\text { ES01_- } \\
\text { c12570_ } \\
390_{-} \\
\text {kom235 }\end{array}$ & $\begin{array}{c}\text { avgbs }_{-} \\
\text {126086.1.41_- } \\
\text { kom234 }\end{array}$ & $\begin{array}{c}\text { GMI_ } \\
\text { ES15_ } \\
\text { c694_- } \\
635_{-} \\
\text {kom231 }\end{array}$ & $\begin{array}{c}\text { GMI_ } \\
\text { ES11 } \\
\text { c2261_ } \\
56_{-} \\
\text {kom230 }\end{array}$ & $\begin{array}{c}\text { GMI_ } \\
\text { ES01_- } \\
\text { c719- } \\
992_{-} \\
\text {kom229 }\end{array}$ & $\begin{array}{c}\text { GMI_- } \\
\text { ES01- } \\
\text { c10157_ } \\
312_{-} \\
\text {kom228 }\end{array}$ & $\begin{array}{r}\text { GMI } \\
\text { ES03 }_{-} \\
\mathrm{c}_{11209} \\
534_{-} \\
\text {kom22 }\end{array}$ \\
\hline $\begin{array}{l}\text { HA05AB42- } \\
20\end{array}$ & 4 & No & B & A & B & B & B & B & A & A & A & A & A & B \\
\hline $\begin{array}{l}\text { HA05AB53- } \\
40\end{array}$ & 4 & No & B & A & B & B & B & B & A & A & A & A & A & B \\
\hline $\begin{array}{l}\text { HA05AB9- } \\
52\end{array}$ & 3 & No & B & A & B & B & B & B & A & A & A & A & A & B \\
\hline $\begin{array}{l}\text { HA08- } \\
\text { 03X31-1 }\end{array}$ & 3 & No & B & A & B & B & B & B & A & A & A & - & A & B \\
\hline IL02-5630 & 4 & No & B & B & B & B & A & A & A & B & B & A & B & A \\
\hline $\begin{array}{l}\text { IL2250-14 } \\
\text { (PI641977) }\end{array}$ & 4 & No & A & B & A & B & B & B & A & B & B & B & B & B \\
\hline $\begin{array}{l}\text { IL3555 } \\
\text { (PI641970) }\end{array}$ & 4 & No & A & B & B & B & B & - & - & A & A & A & B & B \\
\hline Kapp & 4 & No & B & A & A & B & B & B & A & A & A & A & A & B \\
\hline Kolbu & 4 & No & B & A & A & B & B & B & A & B & A & A & A & B \\
\hline $\begin{array}{l}\text { LAO-1134- } \\
022\end{array}$ & 4 & No & B & B & A & B & B & B & A & B & A & A & A & B \\
\hline $\begin{array}{l}\text { LAO-1136- } \\
024\end{array}$ & 4 & No & B & B & A & B & B & B & A & B & A & A & B & B \\
\hline $\begin{array}{l}\text { LAO-1136- } \\
056\end{array}$ & 4 & No & B & A & B & B & A & A & A & B & A & - & A & B \\
\hline Lena & 3 & No & B & A & B & B & B & B & A & A & A & A & A & B \\
\hline Lennon & 4 & No & A & B & A & A & A & B & A & A & B & A & B & B \\
\hline LIPOPLUS & 3 & No & B & A & B & B & A & A & A & A & A & A & A & B \\
\hline Moholt & 4 & No & B & A & B & B & A & A & A & B & B & A & B & A \\
\hline ND001397 & 4 & No & A & A & A & B & B & B & A & A & A & A & A & B \\
\hline Nes & 4 & No & B & A & A & B & B & B & A & B & A & A & A & B \\
\hline Nudist & 4 & No & B & A & A & B & B & B & A & B & A & A & A & B \\
\hline Odal & 4 & No & B & A & B & B & A & A & A & A & A & A & A & B \\
\hline Ogle & 4 & No & B & B & B & B & A & A & A & B & B & A & B & A \\
\hline Olram & 4 & No & B & A & A & B & B & B & A & B & A & A & A & B \\
\hline PI266887-1 & 4 & No & B & B & B & B & B & A & B & B & B & B & B & B \\
\hline Pl263412-1 & 4 & No & B & B & B & B & A & A & A & B & B & B & B & B \\
\hline POL & 4 & No & B & B & B & B & A & A & A & B & B & A & B & A \\
\hline Porter & 4 & No & B & A & A & B & B & B & A & B & B & B & B & B \\
\hline Putnam 61 & 4 & No & A & B & A & B & B & B & - & A & A & A & A & B \\
\hline Racoon & 4 & No & B & A & A & B & B & A & A & A & A & - & A & B \\
\hline Ringsaker & 4 & No & B & A & B & B & A & A & A & B & B & A & B & A \\
\hline $\begin{array}{l}\text { SW } \\
\text { KERSTIN }\end{array}$ & 4 & No & B & A & A & B & B & B & A & B & A & A & A & B \\
\hline SW VAASA & 4 & No & B & A & A & B & B & B & A & A & A & A & A & B \\
\hline Tippecanoe & 4 & No & A & B & A & B & B & B & A & A & A & A & A & B \\
\hline Tyler & 4 & No & A & B & A & B & B & B & A & B & B & B & B & B \\
\hline VAO-58 & 4 & No & B & A & A & B & B & B & - & B & A & A & A & B \\
\hline Zuton & 4 & No & B & A & B & B & B & B & A & A & A & A & A & B \\
\hline Lines $(n)$ & & & 74 & 74 & 74 & 74 & 74 & 74 & 74 & 74 & 74 & 74 & 74 & 74 \\
\hline $\begin{array}{l}\text { Misclassified } \\
(n)\end{array}$ & & & 11 & 50 & 36 & 2 & 18 & 16 & 67 & 33 & 53 & 62 & 48 & 11 \\
\hline Missing data & & & 0 & 0 & 0 & 0 & 0 & 1 & 3 & 3 & 0 & 3 & 4 & 0 \\
\hline $\begin{array}{l}\text { Prediction } \\
\text { accuracy } \\
(\%)\end{array}$ & & & 85 & 32 & 51 & 97 & 76 & 78 & 6 & 54 & 28 & 13 & 31 & 85 \\
\hline
\end{tabular}


of these genes. The present study adds to a growing body of literature that has positioned $P c$ genes on a SNP-based oat consensus map. Information regarding the distribution of $P c$ genes throughout the genome and allelic relationships among genes will deepen as additional genes are mapped.

Pc39 was previously mapped relative to RFLP markers in two populations, Pendek-39/Pendek-48 and OT328/Dumont (Wight et al. 2005). In that study, Pc39 was tightly linked to the RFLP isu2287 in both populations. Interestingly, this RFLP was placed in five locations on the oat consensus map, one of which was Mrg11 at $8.8 \mathrm{cM}$ (Bekele et al. 2018; Chaffin et al. 2016). Therefore, the results of our study are consistent with Wight et al. (2005). However, the present study conclusively located Pc39 on consensus map linkage group Mrg11 (chromosome 1C), which was not possible based upon the previous RFLP maps.

A quantitative trait locus (QTL) conditioning crown rust resistance in oat was previously mapped to the Mrg11 linkage group (Esvelt Klos et al. 2017). This QTL was detected using genome-wide association mapping in a panel of spring oats tested in field nurseries in North Dakota, Minnesota, and Manitoba. This QTL mapped on Mrg11 based on the SNP loci Avgbs_222153 (at 21.9 cM) and GMI_ES17_lrc7896_489 (at 16.2 cM). When taken together, the results of Esvelt Klos et al. (2017) and the present study suggest that Pc39 and the QTL detected by association mapping are different. The most predictive marker for Pc39 (GMI_ES15_c6153_392) and the marker cosegregating with Pc39 (GMI_ES01_c12570_390) were both tested by Esvelt Klos et al. (2017) and were not significantly associated with crown rust reaction. This seems highly unlikely if $P c 39$ was responsible for the QTL effect detected on Mrg 11 by Esvelt Klos et al. (2017). Since the seedling resistance gene Pc39 and the crown rust resistance QTL on Mrg11 reported in Esvelt Klos et al. (2017) are linked on the same linkage group, this genome region can be used as a combination in the future breeding programs to obtain oat cultivars that possess resistance to multiple $P c a$ isolates.

In summary, the race-specific crown rust resistance gene $P c 39$ was mapped to oat consensus map linkage group Mrg11 (oat chromosome 1C) based on linkage to SNP markers. This is the first report of the chromosomal location of $P c 39$. The newly developed KASP markers linked to Pc39 will facilitate the pyramiding of this gene with other crown rust resistance genes. These findings improve our understanding of the genetic basis of crown rust resistance in oat and will facilitate MAS of Pc39 to develop disease-resistant oat cultivars. The potential allelism or linkage of Pc39 and Pc55 should be investigated in future research.

\section{Acknowledgments}

We thank Leslie Bezte and Suzanne Enns for technical support related to DNA marker analyses and Sharon Deceuninck for crown rust pathology support.

\section{Literature Cited}

Admassu-Yimer, B., Bonman, J. M., and Esvelt Klos, K. 2018. Mapping of crown rust resistance gene Pc53 in oat (Avena sativa). PLoS One 13:e0209105.

Bekele, W. A., Wight, C. P., Chao, S., Howarth, C. J., and Tinker, N. A. 2018. Haplotype-based genotyping-by-sequencing in oat genome research. Plant Biotechnol. J. 16:1452-1463.

Brown, P., Duguid, S., Haber, S., Chong, J., Harder, D., Menzies, J., Noll, J., and McKenzie, R. 2001. AC Assiniboia oat. Can. J. Plant Sci. 81:77-79.

Cabral, A. L., Gnanesh, B. N., Fetch, J. M., McCartney, C., Fetch, T., Park, R. F., Menzies, J. G., McCallum, B., Nanaiah, G. K., and Goyal, A. 2014. Oat fungal diseases and the application of molecular marker technology for their control. Pages 343-358 in: Future Challenges in Crop Protection Against Fungal Pathogens. A. Goyal and C. Manoharachary, eds. Springer, New York, NY.

Carson, M. 2011. Virulence in oat crown rust (Puccinia coronata f. sp. avenae) in the United States from 2006 through 2009. Plant Dis. 95:1528-1534.

Chaffin, A. S., Huang, Y. F., Smith, S., Bekele, W. A., Babiker, E., Gnanesh, B. N., Foresman, B. J., Blanchard, S. G., Jay, J. J., Reid, R. W., Wight, C. P., Chao, S., Oliver, R., Islamovic, E., Kolb, F. L., McCartney, C., Mitchell Fetch, J. W., Beattie, A. D., Bjørnstad, A., Michael Bonman, J., Langdon, T., Howarth, C. J., Brouwer, C. R., Jellen, E. N., Klos, K. E., Poland, J. A., Hsieh, T. F., Brown, R., Jackson, E., Schlueter, J. A., and Tinker, N. A. 2016. A consensus map in cultivated hexaploid oat reveals conserved grass synteny with substantial subgenome rearrangement. Online publication. Plant Genome 9. doi: 10.3835/plantgenome2015.10.0102.
Chong, J., and Brown, P. 1996. Genetics of resistance to Puccinia coronata f. sp. avenae in two Avena sativa accessions. Can. J. Plant Pathol. 18:286-292.

Chong, J., Gruenke, J., Dueck, R., Mayert, W., and Woods, S. 2008. Virulence of oat crown rust [Puccinia coronata f. sp. avenae] in Canada during 2002-2006. Can. J. Plant Pathol. 30:115-123.

Chong, J., Leonard, K., and Salmeron, J. 2000. A North American system of nomenclature for Puccinia coronata f. sp. avenae. Plant Dis. 84:580-585.

Chong, J., and Seaman, W. 1994. Incidence and virulence of Puccinia coronata f. sp. avenae in Canada in 1993. Can. J. Plant Pathol. 16:335-340.

Duguid, S., Brown, P., Chong, J., Harder, D., Haber, S., Menzies, J., and Noll, J. 2001. AC Medallion oat. Can. J. Plant Sci. 81:81-83.

Esvelt Klos, K., Yimer, B. A., Babiker, E. M., Beattie, A. D., Bonman, J. M., Carson, M. L., Chong, J., Harrison, S. A., Ibrahim, A. M. H., Kolb, F. L., McCartney, C. A., McMullen, M., Mitchell Fetch, J., Mohammadi, M. Murphy, J. P., and Tinker, N. A. 2017. Genome-wide association mapping of crown rust resistance in oat elite germplasm. Online publication. Plant Genome 10. doi: 10.3835/plantgenome2016.10.0107.

Fleischmann, G., and McKenzie, R. 1968. Inheritance of crown rust resistance in Avena sterilis. Crop Sci. 8:710-713.

Gnanesh, B., Fetch, J. M., Menzies, J., Beattie, A., Eckstein, P., and McCartney, C. 2013. Chromosome location and allele-specific PCR markers for markerassisted selection of the oat crown rust resistance gene $P c 91$. Mol. Breed. 32: 679-686.

Gnanesh, B. N., Fetch, J. M., Zegeye, T., McCartney, C. A., and Fetch, T. 2014 Oat. Pages 51-73 in: Alien Gene Transfer in Crop Plants, vol. 2. Springer, New York, NY.

Gnanesh, B. N., McCartney, C. A., Eckstein, P. E., Fetch, J. W. M., Menzies, J. G., and Beattie, A. D. 2015. Genetic analysis and molecular mapping of a seedling crown rust resistance gene in oat. Theor. Appl. Genet. 128:247-258.

Hammami, I., Allagui, M. B., Chakroun, M., and El-Gazzeh, M. 2010. Natural population of oat crown rust in Tunisia. Phytopathol. Mediterr. 49:35-41.

Hoerner, G. 1919. Biologic forms of Puccinia coronata on oats. Phytopathology 9: 309.

Huang, Y.-F., Poland, J. A., Wight, C. P., Jackson, E. W., and Tinker, N. A. 2014 Using genotyping-by-sequencing (GBS) for genomic discovery in cultivated oat. PLoS One 9:e102448.

Jiráková, H., and Hanzalová, A. 2008. Crown rust pathotypes determined on oats in the Czech Republic from 2004 to 2006 and reaction to oat cultivars. Czech J. Genet. Plant Breed. 44:60-65.

Kebede, A. Z., Friesen-Enns, J. R., Gnanesh, B. N., Menzies, J. G., Fetch, J. W. M., Chong, J., Beattie, A. D., Paczos-Grzęda, E., and McCartney, C. A. 2018 Mapping oat crown rust resistance gene Pc45 confirms association with PcKM. G3 Genes Genomes Genet. 9:505-511.

Kiehn, F., McKenzie, R., and Harder, D. 1976. Inheritance of resistance to Puccinia coronata avenae and its association with seed characteristics in four accessions of Avena sterilis. Can. J. Genet. Cytol. 18:717-726.

Kosambi, D. D. 1943. The estimation of map distances from recombination values Ann. Eugen. 12:172-175.

Leonard, K. 2002. Oat lines with effective adult plant resistance to crown rust. Plant Dis. 86:593-598.

Leonard, K. 2003. Regional frequencies of virulence in oat crown rust in the United States from 1990 through 2000. Plant Dis. 87:1301-1310.

Leonard, K., Anikster, Y., and Manisterski, J. 2004. Patterns of virulence in natural populations of Puccinia coronata on wild oat in Israel and in agricultural populations on cultivated oat in the United States. Phytopathology 94:505-514.

Lin, Y., Gnanesh, B. N., Chong, J., Chen, G., Beattie, A. D., Fetch, J. W. M., Kutcher, H. R., Eckstein, P. E., Menzies, J. G., and Jackson, E. W. 2014. A major quantitative trait locus conferring adult plant partial resistance to crown rust in oat. BMC Plant Biol. 14:250.

Lorieux, M. 2012. MapDisto: Fast and efficient computation of genetic linkage maps. Mol. Breed. 30:1231-1235.

Martens, J., and Dyck, P. 1989. Genetics of resistance to rust in cereals from a Canadian perspective. Can. J. Plant Pathol. 11:78-85.

McCallum, B., Fetch, T., and Chong, J. 2007. Cereal rust control in Canada. Aust. J. Agric. Res. 58:639-647.

McCartney, C., Stonehouse, R., Rossnagel, B., Eckstein, P., Scoles, G., Zatorski, T., Beattie, A., and Chong, J. 2011. Mapping of the oat crown rust resistance gene Pc91. Theor. Appl. Genet. 122:317-325.

McKenzie, R., Martens, J., Brown, P., Harder, D., Nielsen, J., and Boughten, G. 1981. Registration of Fidler oats. Crop Sci. 21:632-633.

Mitchell Fetch, J., Brown, P., Duguid, S., Chong, J., Haber, S., Menzies, J., Ames, N., and Fetch, T. 2003a. Pinnacle oat. Can. J. Plant Sci. 83:97-99.

Mitchell Fetch, J., Brown, P., Duguid, S., Chong, J., Haber, S., Menzies, J., Ames, N., and Fetch, T. 2003b. Ronald oat. Can. J. Plant Sci. 83:101-104.

Murphy, H. C. 1935. Physiologic specialization in Puccinia coronata avenae. USDA Tech. Bull. 433:1-48.

Nazareno, E. S., Li, F., Smith, M., Park, R. F., Kianian, S. F., and Figueroa, M. 2018. Puccinia coronata f. sp. avenae: A threat to global oat production. Mol. Plant Pathol. 19:1047-1060.

Oliver, R. E., Tinker, N. A., Lazo, G. R., Chao, S., Jellen, E. N., Carson, M. L., Rines, H. W., Obert, D. E., Lutz, J. D., Shackelford, I., Korol, A. B., Wight, C. P., Gardner, K. M., Hattori, J., Beattie, A. D., Bjornstad, A., Bonman, J. M., 
Jannink, J. L., Sorrells, M. E., Brown-Guedira, G. L., Mitchell Fetch, J. W., Harrison, S. A., Howarth, C. J., Ibrahim, A., Kolb, F. L., McMullen, M. S., Murphy, J. P., Ohm, H. W., Rossnagel, B. G., Yan, W., Miclaus, K. J., Hiller, J., Maughan, P. J., Redman Hulse, R. R., Anderson, J. M., Islamovic, E., and Jackson, E. W. 2013. SNP discovery and chromosome anchoring provide the first physically-anchored hexaploid oat map and reveal synteny with model species [published correction appears in PLoS One 8. doi: 10.1371/ annotation/9b2ca31c-0aca-44b1-84a1-8bdf8ded7439]. PLoS One 8:e58068.

Paczos-Grzęda, E., and Sowa, S. 2019. Virulence structure and diversity of Puccinia coronata f. sp. avenae P. Syd. \& Syd. in Poland during 2013 to 2015. Plant Dis. 103:1559-1564.

Sanz, M., Loarce, Y., Fominaya, A., Vossen, J., and Ferrer, E. 2013. Identification of RFLP and NBS/PK profiling markers for disease resistance loci in genetic maps of oats. Theor. Appl. Genet. 126:203-218.

Simons, M. D. 1970. Crown rust of oats and grasses. Monograph No. 5. American Phytopathology Society, St. Paul, MN.

Simons, M. D. 1985. Crown rust. Pages 131-172 in: The Cereal Rusts, Volume II: Diseases, Distribution, Epidemiology, and Control. A. Roelfs and W. Bushnell, eds. Academic Press Inc., San Diego, CA.

Simons, M. D., Martens, J. W., McKenzie, R., Nishiyama, I., Sadanaga, K., Sebesta, J., and Thomas, H. 1978. Oats: a standardized system of nomenclature for genes and chromosomes and catalog of genes governing characters. USDA Agricul. Handb. 509.
Tinker, N. A., Bekele, W. A., and Hattori, J. 2016. Haplotag: Software for haplotype-based genotyping-by-sequencing analysis. G3 Genes Genomes Genet. 6:857-863.

Tinker, N. A., Chao, S., Lazo, G. R., Oliver, R. E., Huang, Y.-F., Poland, J. A., Jellen, E. N., Maughan, P. J., Kilian, A., and Jackson, E. W. 2014. A SNP genotyping array for hexaploid oat. Online publication. Plant Genome 7. doi: 10.3835/plantgenome2014.03.0010.

Voorrips, R. 2002. MapChart: Software for the graphical presentation of linkage maps and QTLs. J. Hered. 93:77-78.

Wang, S., Wong, D., Forrest, K., Allen, A., Chao, S., Huang, B. E., Maccaferri, M., Salvi, S., Milner, S. G., Cattivelli, L., Mastrangelo, A. M., Whan, A., Stephen, S., Barker, G., Wieseke, R., Plieske, J., Lillemo, M., Mather, D., Appels, R., Dolferus, R., Brown-Guedira, G., Korol, A., Akhunova, A.R., Feuillet, C., Salse, J., Morgante, M., Pozniak, C., Luo, M.-C., Dvorak, J., Morell, M., Dubcovsky, J., Ganal, M., Tuberosa, R., Lawley, C., Mikoulitch, I., Cavanagh, C., Edwards, K.J., Hayden, M. and Akhunov, E. 2014. Characterization of polyploid wheat genomic diversity using a highdensity 90,000 single nucleotide polymorphism array. Plant Biotechnol. J. 12:787-796.

Wight, C. P., O’Donoughue, L. S., Chong, J., Tinker, N. A., and Molnar, S. J. 2005. Discovery, localization, and sequence characterization of molecular markers for the crown rust resistance genes $P c 38, P c 39$, and $P c 48$ in cultivated oat (Avena sativa L.). Mol. Breed. 14:349-361. 